University of Washington Tacoma

UW Tacoma Digital Commons

9-19-2019

\title{
A Critical Postcolonial and Resilience-Based Framework of Supervision in Action
}

\author{
Alyssa M. Ramírez Stege \\ University of Washington Tacoma, ramstege@uw.edu \\ Mun Yuk Chin \\ Stephanie R. Graham
}

Follow this and additional works at: https://digitalcommons.tacoma.uw.edu/ias_pub

\section{Recommended Citation}

Alyssa Ramirez Stege, Mun Yuk Chin, \& Stephanie R. Graham. (2019). A Critical Postcolonial and Resilience-Based Framework of Supervision in Action. Training and Education in Professional Psychology. https://doi.org/10.1037/tep0000276 


\section{Training and Education in Professional Psychology}

\section{A Critical Postcolonial and Resilience-Based Framework of Supervision in Action}

Alyssa M. Ramírez Stege, Mun Yuk Chin, and Stephanie R. Graham

Online First Publication, September 16, 2019. http://dx.doi.org/10.1037/tep0000276

\section{CITATION}

Ramírez Stege, A. M., Chin, M. Y., \& Graham, S. R. (2019, September 16). A Critical Postcolonial and Resilience-Based Framework of Supervision in Action. Training and Education in

Professional Psychology. Advance online publication. http://dx.doi.org/10.1037/tep0000276 


\title{
A Critical Postcolonial and Resilience-Based Framework of Supervision in Action
}

\author{
Alyssa M. Ramírez Stege, Mun Yuk Chin, and Stephanie R. Graham \\ University of Wisconsin-Madison
}

\begin{abstract}
In this paper, we describe two critical events in clinical supervision between two counseling psychology trainees of color and a White supervisor that demonstrate the need and effectiveness of a supervisory approach that challenges the psychotherapeutic status quo, particularly within the context of our current sociopolitical climate. Using case materials and our reflections, we highlight the significant contributions of relational safety as espoused by a critical postcolonial supervision framework (Hernández \& McDowell, 2010) in cultivating trainees' development as culturally congruent practitioners. This approach confronts hegemonic values of psychotherapy and integrates the cultural worlds of clients, clinicians, and supervisors. We conclude with practical suggestions for building relational safety within the supervisory relationship and future research avenues.
\end{abstract}

\section{Public Significance Statement}

Authors provide two case examples to exemplify the usefulness of challenging the cultural embeddedness of current psychotherapeutic practice and training when working with trainees of color and culturally diverse clients. This critical postcolonial and resilience-based approach specifically centers on developing strong, authentic, and caring therapeutic and supervisory relationships. This perspective to supervision and therapeutic practice facilitated the integration of clinicians' whole cultural selves and the development of innovative and culturally congruent practices with diverse clients.

Keywords: critical, postcolonial, resilience based, multicultural, supervision

Social justice, attention to multicultural issues, and diversity are fundamental values within the field of counseling psychology and have had a significant impact on the development of counseling psychology graduate training programs and professional practices (Sue, Bingham, Porché-Burke, \& Vasquez, 1999; Vera \& Speight, 2003). Scholars have challenged psychologists to redress the socially unjust systems that perpetuate oppression for the most disenfranchised in the population (Toporek, Gerstein, Fouad, Roysircar, \& Israel, 2006; Vera et al., 2003). This perspective was reiterated in the current American Psychological Association Guidelines for Clinical Supervision in Health Service Psychology that promote the empowerment and resilience of culturally diverse populations through focused attention in supervision to the identities and sociocultural contexts of clients as well as supervisees (American Psychological Association, 2014). In response, several theories of supervision and counseling, situated in critical, postcolonial, multicultural, and feminist ideologies were developed that focused on culture, empowerment, and liberation in an effort
Alyssa M. Ramírez Stege, PhD, is an Assistant Professor in the division of Social, Behavioral, and Human Sciences at the School of Interdisciplinary Arts and Sciences at the University of WashingtonTacoma. She received her doctorate in Counseling Psychology from the University of Wisconsin-Madison and completed her internship at Pacific Psychology and Comprehensive Health Clinics in Portland and Hillsboro, Oregon. Her research is focused on how to develop and incorporate culturally grounded psychotherapeutic interventions and supervision practices. Her clinical interests focus on trauma-informed care for underserved and marginalized populations, particularly Spanish-speaking Latinxs.

Mun YuK Chin, MA, is a doctoral candidate in the Department of Counseling Psychology at the University of Wisconsin-Madison and is expected to complete her internship at the University of Utah Counseling Center. Her research focuses on mental health and its connection to experiences of social stigma. Clinically, she is interested working with young adults from marginalized backgrounds.

Stephanie R. Graham, PhD, is a Licensed Psychologist and Clinical Associate Professor in the Department of Counseling Psychology at the University of Wisconsin-Madison where she serves as the director of the Department's training clinic, the Counseling Psychology Training Clinic. She received her doctorate in Counseling Psychology from Auburn University and completed her internship at University Health Services at University of Wisconsin-Madison. Her research and clinical interests including the mental health and wellness of lesbian, gay, bisexual, transgender, and questioning (or queer) folks and underrepresented college students and training and clinical supervision in health service psychology.

CORRESPONDENCE CONCERNING THIS ARTICLE should be addressed to Alyssa M. Ramírez Stege, University of Washington-Tacoma, 1900 Commerce Street, Tacoma, WA 98402-3100. E-mail: amramirezstege@gmail.com 
to address issues of power and oppression in psychotherapeutic work (Butler-Byrd, 2010; Falicov, 2014; Hernández et al., 2010; MacKinnon, Bhatia, Sunderani, Affleck, \& Smith, 2011; ReynagaAbiko, 2010; Singh \& Chun, 2010).

In this paper, we focus on a critical-, postcolonial-, and resilience-based approach to counseling and supervision relationships that challenges the Eurocentric, individualistic psychological theories, and practice that are a result of colonization (Hernández et al., 2010; Hernández-Wolfe, 2011). Colonization is a process of systemic suppression of the beliefs, values, and practices of subordinated cultural groups to champion that of the dominant Western European groups (Hernández et al., 2010; Hernández-Wolfe, 2011). A postcolonial perspective, therefore, exceeds the multicultural stance because it challenges current normativity by contesting the cultural embeddedness of individualistic norms and decontextualized theories on which supervision and therapy are built (Hernández et al., 2010). A critical postcolonial- and resiliencebased approach seeks to develop new frameworks that acknowledge a diversity of experience and integrate multiple ways of knowing and attention to cultural diversity (Butler-Byrd, 2010; Hernández et al., 2010; Reynaga-Abiko, 2010; Singh et al., 2010). By focusing on the role of social context and the power structure in developing and maintaining emotional distress, clients and supervisees are seen as multifaceted, intersectional, and embedded in their context rather than within compartmentalized identities (Hernández et al., 2010; Porter \& Vasquez, 1997; Singh et al., 2010). Additionally, the focus on resilience brings attention to a marginalized individual's ability to rebound and rise above challenging experiences rooted in oppression (Singh et al., 2010).

Supervision scholars have noted several key features of a postcolonial supervisory model that enhances a multicultural approach (Butler-Byrd, 2010; Hernández et al., 2010; Nelson et al., 2006; Porter et al., 1997; Singh et al., 2010). Supervisors are encouraged to honor diverse cultural backgrounds by practicing cultural humility, developing knowledge regarding sociopolitical and historical contexts, and engaging in a holistic approach to healing through experientially based interventions (Butler-Byrd, 2010; Nelson et al., 2006; Porter et al., 1997). Moreover, supervision from a critical postcolonial- and resilience-based model furthers the clinical development of both the supervisee and the supervisor by engaging in an analysis of the influence of power and oppression in both the therapeutic and supervisory encounters (Hernández et al., 2010; Singh et al., 2010). An analysis of power can promote reflective practice through questioning the status quo of dominant groups and practices that continue to marginalize other groups (Hernández et al., 2010; Porter et al., 1997). This model of supervision helps trainees develop critical consciousness, increases one's sense of empowerment, and holds both supervisor and supervisee accountable to help begin to address the inequities that influence client distress (Butler-Byrd, 2010; Hernández et al., 2010).

In supervision, an understanding of the cultural worldviews and frames of reference of both the supervisor and supervisee is needed (Falender, Burnes, \& Ellis, 2013). Supervisors and supervisees must critically examine their own sociopolitical positionality to understand the areas of their privilege and oppression that may be operating in supervision and work to balance power within that relationship (Hernández et al., 2010). Supervisors who demonstrate a critical social awareness and cultural humility can facilitate trusting relationships that encourage supervisees' growth contextualized within their own cultural and social identities (Hernández et al., 2010). This enables supervisees' reflection in their therapeutic (client-therapist) and supervisory (supervisee-supervisor) relationships through attention to the relational power that molds the supervisory triad (Falender et al., 2013; Hernández et al., 2010).

\section{The Clinical Setting}

This contribution focuses on the experiences of two counseling psychology trainees of color (first and second authors) providing psychotherapy exclusively to undergraduate students of color at a departmental training clinic under the supervision of a White psychologist who is a clinical faculty member in a Counseling Psychology Department (third author). The trainees of color had both received master's degrees in counseling and were in their third year of doctoral-level clinical training. They had previous experience with the third author as the departmental training clinic director and group supervisor during their first-year doctoral clinical training experience at the training clinic. In addition, the third author was the instructor for the required supervision practicum course in the department that both student authors were concurrently enrolled in during the clinical experiences described here and included foundational readings for a critical postcolonial and resilience-based supervisory model (i.e., Hernández et al., 2010; Singh et al., 2010).

At the time of this training year, the authors of this article had various training experiences that were specific to serving culturally diverse populations. The first author had built a clinical focus with Spanish-speaking immigrants who had experienced trauma and had completed two community-based mental health practicums specific to this population. The second author is interested in working with college students and young adults from diverse sociocultural backgrounds and had previously completed practicum training in university- and community-based settings. The third author had more than 10 years of postdoctoral experience in providing clinical services to community-based and undergraduate student clients with clinical expertise with lesbian, gay, bisexual, transgender, and questioning (or queer)-identified clients and 7 years working as a supervisor of doctoral-level trainees from diverse sociocultural backgrounds.

This training year coincided with the 2016 U.S. presidential election, which included campaign rhetoric that vilified many marginalized groups (TIME, 2016). Across university campuses, increased incidents of discrimination that targeted minority students were reported (Bauman, 2018; Dickerson \& Saul, 2016). For many of the underrepresented students who were served at the clinic, these current affairs heavily impacted their psychological well-being.

In the following case examples, we feature core components relevant to a critical postcolonial and resilience-based framework, namely the influence of power dynamics and relational safety on successful supervisory and therapeutic processes (Hernández et al., 2010). Clinical and supervisory case examples are shared to highlight supervisory actions that influenced trainee development and the usefulness of critical analyses on clinical skills development. As international trainees and graduate students of color in a predominantly White institution, the first and second authors had 
many shared experiences of marginalization and discrimination both on campus and in their personal life histories with the clients they served. Thus, discussions of the influence of social, political, and cultural factors in our therapeutic encounters were infused throughout supervision, with particular emphasis on relational safety (Butler-Byrd, 2010; Hernández et al., 2010).

Our case examples demonstrate the challenge of building relational safety within both therapeutic and supervisory relationships. These cases highlight the need to critically examine the assumptions of psychotherapy and supervisory processes that are rooted in Western-based beliefs of personhood, emotional expression, and interpersonal interactions. The supervisor's ability to critically examine these assumptions helped build relational safety through attending to the emotional, cognitive, and cultural factors influencing the therapist-client and supervisor-supervisee relationships. Moreover, these cases emphasize the importance of cultural humility in supervision, that is, relinquishing a stance of expertise and being open to having frank discussions about concerns that can emerge within the therapeutic and supervisory dyad (Hernández et al., 2010; Nelson et al., 2006).

Finally, it is important to acknowledge that the clinical and supervisory work described below occurred in a departmental training clinic under the supervision of the training clinic director. We recognize the power inherent in her role within this unique training setting. There may be limitations and/or additional considerations for postcolonial therapeutic and supervisory relationships in other clinical training settings and traditional mental health systems that experience external demands not felt in a training clinic (e.g., hospitals, community mental health agencies).

\section{Case Example 1: Navigating the Complexities of Intraethnic Transference}

As a ciswoman, U.S.-born but Mexican-raised trainee, I (first author) began my work with Sergio* (pseudonym), who had a similar background, in the academic Fall semester of 2016. Being a White-passing Latina, I often take the opportunity in the first clinical encounters to purposefully use code switching from English to Spanish and intentional self-disclosure about my places of origin to make evident some shared cultural backgrounds to build trust and rapport. Using interpersonal strategies such as personalismo (general pleasantness; González-Prendes, Hindo, \& Pardo, 2011) with Latino clients is personally and culturally congruent to me and a way of being that becomes more salient in these intracultural interactions.

Issues of intraethnic countertransference (Comas-Díaz \& Jacobsen, 1991) and the potential for overidentification with Sergio were manifested at the onset of our therapeutic work. Beyond shared cultural identities as Latino, working class, first-generation students, my work with Sergio surfaced some of the more challenging experiences I had in my life including the loss of my father at an early age, a parentified role in my family of origin, and experiences of domestic violence. In the context of training, I often felt challenged to share these experiences with peers and supervisors from different cultural backgrounds for fear of reifying negative stereotypes of Latinos and lack of understanding the sociopolitical and historical context of family development and trauma in Mexico. Concurrently, within the broader social context, the then-U.S. presidential candidate Donald Trump was expressing discrimina- tory messages of Mexican men in particular, whom he described as rapists and criminals (BBC, 2016). Consequently, a parallel process began within the therapeutic and supervisory relationships in which I was challenged to disclose past traumatic experiences with my supervisor similarly to those that Sergio had difficulty disclosing to me.

Hierarchies of power and the role of cultural differences and similarities influenced the dynamic of building relational safety in therapy and supervision. Gendered societal and Latino cultural norms of hypermasculinity and machismo (Arciniega, Anderson, Tovar-Blank, \& Tracey, 2008) may restrict men's emotional expression to comply with expectations to be violent, rude, and controlling. For Sergio, these traits likely seemed valuable and protective when living in spaces in which random violence was common. Thus, the vulnerability of a therapeutic setting, discussing fear, and the need for care likely felt threatening to Sergio. In supervision, disclosing my countertransferential reactions based on my past experiences of domestic violence with my White American supervisor (third author) felt threatening in a different way. Hegemonic Eurocentric cultural norms regarding professionality made me wonder how much I should disclose in a supervisory setting and fear how a White supervisor might respond while managing feelings of shame and grief related to these past experiences.

My supervisor's intentional use of power sharing and role modeling how to build relational safety in supervision helped me translate skills into my therapeutic work with Sergio. My supervisor was curious, caring, personable and had a collaborative stance. Supervision often began with a general check-in which led to discussions on how my life outside the training clinic, embedded in the sociopolitical climate of the time, influenced my clinical work. In turn, my supervisor also revealed some of her personal challenges that impacted on her work as a therapist over the course of her career, modeling how to use my emotional experiences to become more attuned in my work with my clients. She invited a critical analysis of client, therapist, and supervisor positionality and helped integrate my cultural insights into a comprehensive clinical conceptualization of Sergio. She challenged me to consider the ways in which Sergio and my shared experiences might both help and hinder dynamic processes in the therapeutic encounter, specifically considering how culture mattered. Consequently, I used similar therapeutic interventions modeled in supervision, for example, using plática (i.e., small talk) as a culturally sanctioned form of rapport building with Sergio (Gallardo, 2013), and explicitly discussed how societal expectations for Latino men (e.g., being stereotyped as criminals) influenced his presenting concerns and therapeutic process.

A moment of challenge emerged later in this case when my supervisor asked me to consider whether Sergio's general friendliness and laughter during our sessions were culturally expected norms of interaction or whether these might be signs of a transferential reaction. I had assumed this mode of interaction reflected personalismo as with many Latinx clients. However, a deeper analysis of our dynamic exposed a common intraethnic transferential reaction, Sergio's idealization of me as the omnipotent therapist (Comas-Díaz et al., 1991). Given my educational status and therapeutic role, Sergio could have seen me as the survivor of projected shared experiences of oppression. Rooted in this client's 
reaction were similar fears I had experienced of exposing racebased trauma and stereotype threat with my supervisor.

In this case, relational safety was essential to my professional growth and therapeutic effectiveness, particularly within the dynamics of a cross-cultural supervisor-supervisee relationship. Instead of a surface cultural analysis (e.g., all Latinx clients engage in plática), my supervisor asked me to consider whether plática was impeding us from discussing deeper emotional experiences and possibly colluding with my client's transferential reaction. My supervisor enacted key components of a critical postcolonial and resilience-based framework: she invited discussions of our intersectional identities, she demonstrated cultural humility by prioritizing spending time getting to know me as a cultural being, built trust through the use of intentional self-disclosure, and responded to my disclosures by highlighting the strengths of my life experiences in building my therapeutic self. Because of our collaborative and trusting supervisory relationship, I could integrate her feedback and curiosity rather than assuming that she did not understand the cultural nuances of this case because she lacked a shared cultural experience. This experience influenced my own work as a supervisor-in-training and showed me the importance of welcoming my supervisees' whole cultural selves into supervision and, in turn, how to share myself with them. It is from this starting point that we can then think critically together about our psychotherapeutic assumptions. Developing relational safety has empowered me to have open, caring, and candid conversations about my supervisees' as well as my own therapeutic work in the context of past personal histories and broader sociopolitical issues.

\section{Case Example 2: Constructing a Culturally Congruent Practice}

As a queer international ciswoman of color, I (second author) had completed an intake session with Raha* (pseudonym), a young Muslim woman of color who divulged minimally about herself and her depression. Raha exhibited a significant level of guardedness and discomfort, and I struggled to engage with her despite using the usual techniques in which I was taught to generate rapport with my clients. For example, I posed open-ended questions, shared my therapeutic style, and disclosed to Raha my status as a student who was born and raised in Malaysia, where Islam is practiced by the majority of its people. During the course of supervision with the third author of this article, I was made aware of the ways in which I recapitulated hegemonic practices of psychotherapy based on common Western values and norms of physical and clinical interactions. Consequently, supervision served as a space that challenged me to cultivate a more inclusive and culturally responsive experience for Raha. In doing so, I too was able to become more culturally congruent as a practitioner.

In supervision, I reflected on the potential reasons for Raha's discomfort in our therapy room. First, I wondered whether Raha, marked by her hijab and skin color, may be enduring Islamophobia and racism routinely in the context of widespread anti-Muslim rhetoric that accompanied the election season (Nadal, Griffin, Hamit, Leon, \& Tobio, 2012). Given this and her status as a student of color on a predominantly white campus, it was likely that Raha was feeling unsafe. Informed by her lived experiences as a Muslim woman of color, Raha's guardedness in session may have reflected her caution toward the broader political and social environment and consequently, served to protect her (Çiftçi, Jones, \& Corrigan, 2012; Inayat, 2007). It was imperative that I facilitated a sense of physical and relational safety for Raha in therapy. Second, I learned that Raha had previously seen a therapist for anxiety and that throughout their work, both had sat on the floor together. This seating arrangement also reflected how Raha gathered with her family members for religious and communal events. This practice of Raha's resonated with my experiences at home, where I frequently sat on the floor with family, friends, and guests on different occasions. As I shared these thoughts with my supervisor, we discussed the implications of the existing configuration of our therapy room, which stipulated that both the client and the therapist be seated in chairs to face each other. We discussed the configuration's rootedness in Western norms of physical space and that potentially it may have imposed on Raha the expectation that she would be engaging in psychotherapy that is steeped in hegemonic values that are incongruent to her. Consequently, my supervisor asked, "Have you considered asking Raha to sit with you on the floor?" She encouraged me to collaborate with Raha to create a space that felt safe and congruent. Mindful of the power I wielded as the therapist, I invited Raha to sit on floor with me in the next session, and we discussed ways in which we could create a space that felt comfortable for her. Together we crafted a ritual of rearranging the furniture to make room for our therapeutic space. Immediately Raha appeared more relaxed and disclosed more openly during our meeting.

In hindsight, my supervisor's invitation for me to literally dismantle the default setup in our therapy room illustrates a powerfully corrective experience that enhanced my relational safety with her and with my client. Specifically, my supervisor used her authority responsibly (i.e., offering permission) to encourage me to honor and respond to both my and Raha's cultural practices and preferences in therapy (Hernández et al., 2010). As student with intersecting minority identities, I reflected on the amplified sense of marginalization that I experienced during the election year that disempowered me from engaging in clinical practices that were culturally congruent to me. Instead it felt safer for me to use default practices of psychotherapy that are often reflective of dominant values, even though they sometimes felt divorced from my sociocultural experiences and practices. Thus, it was crucial to have my supervisor's support and encouragement as I inhabited my clinical role in a way that felt more culturally familiar to me.

Throughout my work with Raha, my supervisor continued to challenge me to expand my use of culturally relevant interventions. For example, as we inched closer to discussing the intergenerational trauma that Raha was unable to articulate initially, she inquired "How about encouraging her to draw instead of talk? How about a genogram?" I realized that I had a strong reliance on words as our sole medium for communication, which in this case was not effective because it was not adequately responding to Raha's needs, given her socialization to silence her suffering and pain. My reliance on speech was also rooted in a Eurocentric standard of psychotherapy. By using a transgenerational trauma and resilience genogram (Goodman, 2013) to visually depict her relationships with her family members, I would uncover the painful yet unspoken traumatic experiences endured by Raha and her family members. I would go on to have Raha share more about herself and family through art, to instill hope for change and healing by highlighting narratives of resilience amid suffering, and 
to use touch as a form of comfort as we developed our therapeutic foundation.

My interactions with my supervisor and with Raha were pivotal for my professional development. Not only did my supervisor challenge me to think fluidly and critically about how we do psychotherapy, but also she facilitated my capacity to implement such critical thought in a manner that empowered my client and myself as trainee of color. Her direct, collaborative, and curious stance enhanced the relational safety of our supervisory relationship, which facilitated my openness and vulnerability to identifying and working on my areas of growth (e.g., hegemonic assumptions and practices of psychotherapy) with Raha (Hernández et al., 2010; Nelson et al., 2006). For example, I was encouraged to consider how the Eurocentric tradition of sitting in chairs facing each other felt unfamiliar and stifling for my client given her intersecting identities and experiences. Through our supervisory relationship and work, I developed a habit of questioning the traditions of Westernized psychotherapy and redefining my interventions based on the intersections between my clients' and my identities, histories, and preferences. Simultaneously I was learning how to conduct clinical supervision and saw in my supervisor a role model for cultivating relational safety in supervision while prioritizing effective client care.

\section{Supervisor Reflections}

Supervising as a White, cisgender, female, queer counseling psychologist has provided myriad of opportunities and challenges particularly as the supervision literature has matured and my experience as a supervisor for trainees of color has deepened. As a midcareer counseling psychologist with primary roles as a training clinic director and supervisor, recent scholarship (e.g., Hernández et al., 2010) delineating a clinical supervisor's role in challenging internalized and institutionalized practices by embracing a critical, postcolonial stance, felt like a call to action for both the profession and my own practice. It is from this perspective that I offer my reflections on the above case examples. Interventions focused on relational safety and modeling in supervision will be highlighted.

For both of these cases, the first and second authors of this article, my supervisees, had an accurate assessment of relevant clinical issues and yet both were reticent in discussing the client issues described in the above scenarios. At the time, it was unclear what might be contributing to this dynamic as it could have been a number of factors including fear of sharing their ideas or wonderings with me, inexperience with the clinical presentation, our relational dynamic, or issues related to shared experiences with the client. The challenge for me was to stay curious while exploring the content and process-related themes from a critical, resiliencebased stance, both for the benefit of the supervisee and the client. For example, I wondered how could I increase the second author's self-efficacy so that she could reframe Raha's discomfort in the therapy room as protective, given her experiences as a Muslim student of color and feel empowered to challenge traditional paradigms of how we sit in a therapy space? How might I help the first author hold both the idea that Sergio's presentation may be hindering his ability to share his pain with her and an artifact of his experiences with racism and nationalism as a Latino immigrant and a function of their shared identities? I framed these wonderings, with patience and curiosity, to my supervisees. There were not right or wrong directions in this conversation. Rather, it was an open, respectful space of collaborative learning.

In our work, because we had spoken frequently about our relationship, sociocultural contexts and positional power, and the diversity of identities and experiences within the supervisory triads, there was a high level of relational safety. High relational safety allowed us to find ways to explore the clinical issues without suffocating the trainees' knowing of the client, the case, and their therapist selves (Schon, 1983). As the supervisor, this meant both recognizing my layers of privilege in these relationships (e.g., White, U.S. born, and supervisory) and then actively sharing power with my supervisees. I relinquished my need for knowing to allow for trainee reflexivity, curiosity, and sense of empowerment. It also meant acknowledging their experiences (as well as their clients) with racism, nationalism, and sexism and the impact of these experiences on the process and content of the clinical and supervisory relationships. We were then able to develop strategies that embraced the experiences and sociocultural contexts of both the trainees and the clients and critically challenge the ways that institutionalized power structures operate in therapy and supervision (Hernández et al., 2010).

During our work, I was acutely aware that both my supervisees were learning to be supervisors themselves in a class in which I was the instructor, so modeling a critical, postcolonial relational supervisory approach felt particularly important. I wanted not only for our work to be meaningful in their development as clinicians but also as supervisors-in-training. Meaningful supervisory relationships that allow us to know and value each other as cultural beings with unique experiences can facilitate healing with trainees. During supervision, we talked about our lives, our challenges, in the current political and campus climate. We made space to be angry, afraid, and hopeful and then discussed what this meant for both the supervisory and clinical work. We shared food together, a cultural practice from my familial and cultural background. Trainee evaluation was viewed as a reflection together on the supervisees' skills and the understanding and application of the evaluation items with a developmental and sociocultural focus. As the supervisor, this meant valuing and knowing each other as the relational foundation of all psychological work.

A focus on relational safety in supervisory relationships feels particularly important in a political climate in which individuals with marginalized identities question their belonging in the United States, more broadly, and within our academic institutions and professional training programs in psychology. The supervision described here occurred at a training clinic within a Department of Counseling Psychology highly focused on social justice and multiculturalism. Trainees within this context, particularly trainees of color working with undergraduate students of color, readily and openly provided multiple layers of cultural context to examine from the framework discussed here. We recognize that this may not be the case within other programs, campuses, agencies; however, the call to action remains for those of us with power in supervisory relationships to continue to challenge practices rooted in colonialism and hegemony.

\section{Clinical Implications}

The supervisory case examples we discuss here illustrate the effectiveness and general need for a critical postcolonial and 
resilience-based framework to provide culturally congruent supervision (Hernández et al., 2010). We emphasize here the development of relational safety in the supervisory and therapeutic relationship as an important element that can facilitate the implementation of this framework. Through this supervisory approach, both trainees of color felt they were able to find their unique voice as clinicians and effectively integrate their cultural selves into the therapeutic encounter. This was evident by an increased sense of self-efficacy working with culturally diverse clients, understanding the sociocultural and political dynamics that influence clients' presenting concerns, and the ability to change the therapeutic setting and/or interventions to increase cultural congruency to meet clients' needs. In turn, as treatment progressed for Sergio and Raha, they demonstrated more adaptive and authentic ways of connecting with themselves (e.g., identifying their preferences and needs, understanding the influence of discrimination in their everyday life experiences) and others (e.g., taking risks to build new relationships), exhibited a stronger sense of self-esteem, and experienced less severe mood-related and trauma-based symptoms.

The authors believe a critical postcolonial and resilience-based training approach was transformative for clients, trainees, and the supervisor. The first and second author found this training experience to be unique in deconstructing the basic assumptions of psychotherapeutic practice and inviting input, critique, and dialogue to include broader sociocultural and political concerns into clinical case conceptualizations and treatment. In this training setting, cultural factors that influence clients were not discussed as separate from their psychological distress but rather the whole therapeutic encounter was analyzed as a culturally embedded experience to deconstruct, transform, and develop an overall culturally competent practice.

A critical postcolonial and resilience-based supervision aims to redress the hegemonic Westernized view of psychotherapeutic practice often incongruent with different cultural values and belief systems (Utsey, Hammar, \& Gernat, 2005). Thus, we believe this is a framework that is helpful to enact with all trainees working with a wide range of clients. Psychologists who are multiculturally aware should strive to understand the systems of power that maintain and perpetuate the marginalization of the most disenfranchised populations (Vera et al., 2003). This in-depth analysis has the potential to positively influence the therapeutic and supervisory encounters to transform and enhance the effectiveness of therapeutic interventions. Furthermore, through a critical postcolonial and resilience-based perspective, diverse experiences are valued, encouraged, integrated, and implemented, helping trainees find their own unique and culturally congruent voice as future practitioners.

As trainees and supervisors, our practice is embedded within our sociopolitical contexts. Importantly, these case examples have emerged during a political moment in the United States where sectors of the population are highlighting the disenfranchisement of marginalized people and challenging the status quo. For trainees of color, lived experiences of marginalization accompany them in clinical and supervisory roles. Thus, supervisors must attend to the intersections of trainee and client experiences that are rooted in racism, oppression, and trauma. By fostering relational safety with their trainees, supervisors are ultimately building a conducive foundation upon which they can empower trainees to work more authentically and effectively with their clients. For White supervisors working with trainees of color, it is important to go beyond acknowledging their power differential and to take risks in engaging with their trainees repeatedly and deeply around their cultural experiences and identities (Hernández \& Rankin, 2008). By using our case examples, we hope to demonstrate the ways through which supervisors can use their authority responsibly to immerse themselves with their trainees' experiences to encourage their growth as culturally congruent clinicians.

The type of critical analysis inherent in a critical postcolonial and resilience-based framework must be modeled and encouraged by supervisors, particularly those who embody identities that are traditionally privileged in society. Supervisors must work to develop relational safety to reassure supervisees that they can bring their whole cultural selves into supervision and their therapeutic work. Similarly, supervisors can serve as role models by bringing their own cultural selves in supervisory discussions through power sharing practices, for example, the use of intentional supervisor self-disclosure, engagement in discussions about sociocultural and political factors, and expressing trust in supervisees' cultural knowledge. We believe this framework can be particularly useful in cross-cultural supervisory interactions. Rather than having supervisors prove cultural competence to supervisees of color, both supervisor and supervisee are engaged in a continual dialogue and experiential practice of positioning their cultural selves in the supervisory and therapeutic dyads, wondering how and when different cultural experiences influence therapeutic work. In this framework, cultural factors are not static or essentializing knowledge, they are dynamic beliefs, values, and orientations that are continually reviewed, considered, and integrated in psychotherapy.

Whereas there is growing scholarship on the perspectives and experiences of clinical trainees of color in supervision (e.g., Jernigan, Green, Helms, Perez-Gualdron, \& Henze, 2010), more is needed to support critical postcolonial supervisory, and clinical training. We provide case examples to elucidate this approach. However, further empirical research is needed to test the effectiveness of this and other cultural competency paradigms (Benuto, Casas, \& O'Donohue, 2018). For example, future research can examine the effective ways in which supervisors and instructors can contribute to trainees' growth as culturally congruent practitioners as well as its impact on their clients' progress. Additionally, the use of outcome measures for clients and the therapeutic encounter and supervisees and the supervisory relationship could test the effectiveness of this supervisory approach. Future work can also elucidate concrete actions that supervisors and supervisors-in-training can take to enhance their capacity to generate relational safety with their supervisees. In addition to offering concrete examples on how these practices can be accomplished within a departmental training setting, we hope to demonstrate the interconnectedness of psychotherapy and supervision as cultural encounters (Falicov, 2014).

Finally, we provide a few suggestions for curriculum development from a critical postcolonial and resilience-based framework. We believe a strong foundation of this approach is an emphasis on understanding how sociopolitical power structures influence access and opportunity to resources and, in turn, clients' overall wellness. A decolonized perspective in training needs to teach students to critically consider the role of power dynamics in how we build intrapsychic interpretations of distress, understand why 
conditions are the way they are, and theorize how conditions can be undone and redone (Goodman \& Gorski, 2016). This perspective would ideally be infused throughout courses into the discussion of how all psychological theories, assessment, and interventions are influenced by a hegemonic Westernized worldview. Including instruction on psychological theories that purposefully seek to disrupt the status quo, such as liberation psychology (Martín-Baró, 1994), could provide trainees with foundational knowledge to enact change. However, the training environment needs to move beyond an acknowledgment of systemic barriers and put knowledge into action. Thus, specific training opportunities are needed, for example, developing clinical training opportunities similar to those developed for advocacy training (see Goodman, Wilson, Helms, Greenstein, \& Medzhitova, 2018) in which students work closely with marginalized communities and integrate multiple levels of intervention in their practice.

\section{References}

American Psychological Association. (2014). Guidelines for clinical supervision in health service psychology. Retrieved from http://apa.org/ about/policy/guidelines-supervision.pdf

Arciniega, G. M., Anderson, T. C., Tovar-Blank, Z. G., \& Tracey, T. J. G. (2008). Toward a fuller conception of Machismo: Development of a traditional Machismo and Caballerismo Scale. Journal of Counseling Psychology, 55, 19-33. http://dx.doi.org/10.1037/0022-0167.55.1.19

Bauman, D. (2018). After 2016 election, campus hate crimes seemed to jump. Here's what the data tell us. Chronicle of Higher Education. Retrieved from https://www.chronicle.com/article/After-2016-ElectionCampus $/ 242577$

BBC. (2016). 'Drug dealers, criminals, rapists': What Trump thinks of Mexicans. Retrieved from https://www.bbc.com/news/video_and_audio/ headlines/37230916/drug-dealers-criminals-rapists-what-trump-thinksof-mexicans

Benuto, L. T., Casas, J., \& O'Donohue, W. T. (2018). Training culturally competent psychologists: A systematic review of the training outcome literature. Training and Education in Professional Psychology, 12, 125134. http://dx.doi.org/10.1037/tep0000190

Butler-Byrd, N. M. (2010). An African American supervisor's reflections on multicultural supervision. Training and Education in Professional Psychology, 4, 11-15. http://dx.doi.org/10.1037/a0018351

Çiftçi, A., Jones, N., \& Corrigan, P. W. (2012). Mental health stigma in the Muslim community. Journal of Muslim Mental Health, 7, 17-32.

Comas-Díaz, L., \& Jacobsen, F. M. (1991). Ethnocultural transference and countertransference in the therapeutic dyad. American Journal of Orthopsychiatry, 61, 392-402. http://dx.doi.org/10.1037/h0079267

Dickerson, C., \& Saul, S. (2016, November 10). Campuses confront hostile acts against minorities after Donald Trump's election. New York Times. Retrieved from https://www.nytimes.com/2016/11/11/us/policeinvestigate-attacks-on-muslim-students-at-universities.html

Falender, C. A., Burnes, T. R., \& Ellis, M. V. (2013). Multicultural clinical supervision and benchmarks: Empirical support informing practice and supervisor training. Counseling Psychologist, 41, 8-27. http://dx.doi .org/10.1177/0011000012438417

Falicov, C. J. (2014). Psychotherapy and supervision as cultural encounters: The multidimensional ecological comparative approach framework. In C. A. Falender, E. P. Shafranske, \& C. J. Falicov (Eds.), Multiculturalism and diversity in clinical supervision: A competency-based approach (pp. 29-58). Washington, DC: American Psychological Association. http://dx.doi.org/10.1037/14370-002

Gallardo, M. E. (2013). Context and culture: The initial clinical interview with the Latina/o client. Journal of Contemporary Psychotherapy, 43, 43-52. http://dx.doi.org/10.1007/s10879-012-9222-8
González-Prendes, A. A., Hindo, C., \& Pardo, Y. (2011). Cultural values integration in cognitive-behavioral therapy for a Latino with depression. Clinical Case Studies, 10, 376-394. http://dx.doi.org/10.1177/ 1534650111427075

Goodman, L. A., Wilson, J. M., Helms, J. E., Greenstein, N., \& Medzhitova, J. (2018). Becoming an advocate: Processes and outcomes of a relationship-centered advocacy training model. Counseling Psychologist, 46, 122-153. http://dx.doi.org/10.1177/0011000018757168

Goodman, R. D. (2013). The transgenerational trauma and resilience genogram. Counselling Psychology Quarterly, 26, 386-405. http://dx .doi.org/10.1080/09515070.2013.820172

Goodman, R. D., \& Gorski, P. C. (Eds.). (2016). Decolonizing "multicultural" counseling through social justice. New York: Springer.

Hernández, P., \& McDowell, T. (2010). Intersectionality, power, and relational safety in context: Key concepts in clinical supervision. Training and Education in Professional Psychology, 4, 29-35. http://dx.doi .org/10.1037/a0017064

Hernández, P., \& Rankin, P. (2008). Relational safety in supervision. Journal of Marital and Family Therapy, 34, 58-74.

Hernández-Wolfe, P. (2011). Decolonization and "mental" health: A Mestiza's journey in the Borderlands. Women \& Therapy, 34, 293-306. http://dx.doi.org/10.1080/02703149.2011.580687

Inayat, Q. (2007). Islamophobia and the therapeutic dialogue: Some reflections. Counselling Psychology Quarterly, 20, 287-293. http://dx.doi .org/10.1080/09515070701567804

Jernigan, M. M., Green, C. E., Helms, J. E., Perez-Gualdron, L., \& Henze, K. (2010). An examination of people of color supervision dyads: Racial identity matters as much as race. Training and Education in Professional Psychology, 4, 62-73. http://dx.doi.org/10.1037/a0018110

MacKinnon, C. J., Bhatia, M., Sunderani, S., Affleck, W., \& Smith, N. G. (2011). Opening the dialogue: Implications of feminist supervision theory with male supervisees. Professional Psychology, Research and Practice, 42, 130-136. http://dx.doi.org/10.1037/a0022232

Martín-Baró, I. (1994). Writings for a liberation psychology. Cambridge, MA: Harvard University Press.

Nadal, K., Griffin, K. E., Hamit, S., Leon, J., \& Tobio, M. (2012). Subtle and overt forms of Islamophobia: Microaggressions toward Muslim Americans. Journal of Muslim Mental Health, 6, 15-367. http://dx.doi .org/10.3998/jmmh.10381607.0006.203

Nelson, M. L., Gizara, S., Crombach Hope, A., Phelps, R., Steward, R., \& Weitzman, L. (2006). A feminist multicultural perspective on supervision. Journal of Multicultural Counseling and Development, 34, 105115. http://dx.doi.org/10.1002/j.2161-1912.2006.tb00031.x

Porter, N., \& Vasquez, M. (1997). Covision: Feminist supervision, process, and collaboration. In J. Worell \& N. G. Johnson (Eds.), Shaping the future of feminist psychology: Education, research, and practice (pp. 155-171). Washington, DC: American Psychological Association Press. http://dx.doi.org/10.1037/10245-007

Reynaga-Abiko, G. (2010). Opportunity amidst challenge: Reflections of a Latina supervisor. Training and Education in Professional Psychology, 4, 19-25. http://dx.doi.org/10.1037/a0017052

Schon, D. (1983). The reflective practitioner. San Francisco, CA: JosseyBass.

Singh, A., \& Chun, K. Y. S. (2010). "From the margins to the center": Moving towards a resilience-based model of supervision for queer people of color supervisors. Training and Education in Professional Psychology, 4, 36-46. http://dx.doi.org/10.1037/a0017373

Sue, D. W., Bingham, R. P., Porché-Burke, L., \& Vasquez, M. (1999). The diversification of psychology: A multicultural revolution. American Psychologist, 54, 1061-1069. http://dx.doi.org/10.1037/0003-066X.54 .12 .1061

TIME. (2016, November 11). How historians of tomorrow will interpret Donald Trump's election. TIME. Retrieved from http://time.com/4565025/futurehistorians-election-week/ 
Toporek, R. L., Gerstein, L. H., Fouad, N. A., Roysircar, G., \& Israel, T. (Eds.). (2006). Handbook for social justice in counseling psychology: Leadership, vision, and action. Thousand Oaks, CA: Sage Publishers.

Utsey, S. O., Hammar, L., \& Gernat, C. A. (2005). Examining the reactions of White, Black, and Latino/a counseling psychologists to a study of racial issues in counseling and supervision dyads. Counseling Psychologist, 33, 565-573. http://dx.doi.org/10.1177/0011000005276493

Vera, E. M., \& Speight, S. L. (2003). Multicultural competence, social justice, and counseling psychology: Expanding our roles. Counseling
Psychologist, 31, 253-272. http://dx.doi.org/10.1177/001100000 3031003001

Received August 2, 2018

Revision received June 4, 2019

Accepted June 10, 2019 